\title{
Guía para el diagnóstico de laboratorio de enfermedad fúngica invasora por hongos filamentosos
}

\author{
Rodrigo Cruz
}

Early diagnosis and timely treatment are critical in Invasive Fungal Disease (IFD) caused by filamentous fungi in immunocompromised patients. Clinical features of IFD are nonspecific; therefore, images (CT scan), direct microscopic examination, staining and cultures of clinical samples and galactomannan determination in blood or BAL, are substantial. This guideline provides recommendations on transport and sample processing, including stains and culture media requirements. It also describes clues for diagnosis of major genera and species of Aspergillus.

Key words: Invasive fungal disease, aspergillosis, diagnosis, keys.

Palabras clave: Enfermedad fúngica invasora, aspergilosis, diagnóstico, claves.

\section{Introducción}

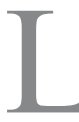

a enfermedad fúngica invasora (EFI) por hongos filamentosos es una causa frecuente de morbimortalidad en pacientes inmunocomprometidos ${ }^{1-3}$. Estas infecciones son más frecuentes en pacientes oncohematologicos que cursan con neutropenia, en especial aquellos con leucemia mieloide aguda; sin embargo, existen otros grupos de riesgo (pacientes sometidos a trasplante de órganos sólidos o de precursores hematopoyéticos, enfermedad injerto contra hospedero, enfermedad granulomatosa, SIDA, etc.) donde también pueden diagnosticarse ${ }^{3-5}$.

La EFI por hongos filamentosos es provocada principalmente por el género Aspergillus, y si bien A. fumigatus predomina ampliamente, otras especies de este género (A. flavus, A. niger, A. terreus y A. nidulans), Fusarium, Scedosporium y taxas pertenecientes a los mucormycetes se diagnostican con cierta frecuencia ${ }^{5-7}$.

Las principales localizaciones de estas infecciones son pulmonares y senos paranasales; sin embargo, también pueden presentarse en piel, sistema nervioso central y formas diseminadas ${ }^{8,9}$.

El diagnóstico debe ser realizado con un bajo margen de error y con la mayor rapidez posible para iniciar precozmente el tratamiento, y así mejorar el pronóstico de los pacientes ${ }^{10,11}$.

Las manifestaciones clínicas son inespecíficas, coincidiendo con otros agentes, por lo que no son de mayor utilidad en el diagnóstico ${ }^{12}$. La imagenología convencional es de poca utilidad por la aparición tardía e inespecífica de las imágenes, razón por la cual la tomografía axial computada (TAC) debe ser indicada precozmente por su alto valor predictor positivo ${ }^{13}$. El signo del halo se presenta precozmente en micosis pulmonar con un alto valor, tanto en la sensibilidad como en la especificidad; no obstante, también puede ocurrir en infecciones por mucormycetes (signo del halo inverso), Fusarium spp, Scedosporium spp y P. aeruginosa. El signo del aire creciente generalmente se presenta tardíamente, cuando el paciente se recupera de la neutropenia ${ }^{13,14}$.

La detección del antígeno galactomanano de la pared de Aspergillus en sangre o en lavado broncoalveolar (LBA) es un examen con una alta sensibilidad y especificidad en pacientes onco-hematológicos, tanto adultos como en niños, por lo que se recomienda realizar en todos aquellos pacientes en que se sospecha una aspergilosis invasora $^{15-17}$. Su utilidad en otros grupos de pacientes inmunocomprometidos no ha sido bien demostrada ${ }^{18}$.

El diagnóstico con microscopia directa y cultivo en agar Sabouraud (AS) tiene una sensibilidad que va desde $11 \%$ hasta $80 \%$, dependiendo del tipo de muestra, enfermedad de base y momento del diagnóstico de la infección; sin embargo, no siempre es posible tomar muestras invasoras (lavado broncoalveolar o biopsias) a estos pacientes, debido a las condiciones basales y complicaciones que presentan ${ }^{16,19,20}$.

El objetivo de la presente guía es describir las técnicas con que deben contar los laboratorios clínicos para el diagnóstico de EFI por hongos filamentosos, además de entregar algunas claves para la identificación de los géneros más comunes y las principales especies de Aspergillus.
Universidad de Valparaíso, Chile.

Cátedra de Micología.

Sin conflictos de interés . Financiamiento: fondos de la Cátedra de Micología de la Universidad de Valparaíso.

Recibido: 3 de marzo de 2013 Aceptado: 3 de marzo de 2014

Correspondencia a: Rodrigo Cruz Choappa rcruzchoappa@mail.com 


\section{Observación microscópica directa y cultivo micológico}

Si un paciente tiene factores de riesgo para EFI y presenta lesiones pulmonares, sinusales o en otra localización, se debe intentar obtener una muestra, ya sea por lavado bronco-alveolar, aspirado traqueal, esputo inducido o biopsia pulmonar o de la mucosa nasosinusal. Las condiciones de almacenamiento, transporte y procesamiento son fundamentales para obtener un mejor rendimiento de las distintas muestras.

\section{Lavado broncoalveolar}

Objetivo: Obtener un lavado del compartimiento alveolar para la observación de hifas en el examen microscópico directo y desarrollo de las distintas especies en el cultivo.

Obtención de la muestra: Mediante fibrobroncoscopio impactado en un bronquio subsegmentario, se instila solución salina ( $\mathrm{NaCl} 9 \%$ estéril) entre 50 y $100 \mathrm{ml}$ (en pediatría $1-2 \mathrm{ml} / \mathrm{kg}$ de peso, máximo $20-30 \mathrm{ml}$ ) y luego se aspira hasta obtener el máximo de volumen líquido posible (aproximadamente el $50 \%$ de lo instilado). Las muestras deben ser recolectadas en tubos estériles con tapa rosca. No agregar ningún líquido fijador.

Condiciones de almacenamiento y transporte: $\mathrm{Si}$ su traslado no es posible de efectuar al momento, conservar a $4{ }^{\circ} \mathrm{C}$ hasta 2 a $4 \mathrm{~h}$. Debe ser enviada al laboratorio con unidad refrigerante.

Procesamiento: Centrifugar a $5.000 \mathrm{rpm}$ durante 5 min, eliminar el sobrenadante y del pellet realizar visión microscópica directa con lactofenol con azul de algodón, $\mathrm{KOH} 20 \%$ o calcofluor y sembrar dos tubos con AS a $37^{\circ} \mathrm{C}$ por 7 días.

\section{Aspirado traqueal (AT) o esputo inducido (EI)}

Objetivo: Observación de hifas en el examen microscópico directo y desarrollo de las distintas especies en el cultivo.

Figura 1. Hifas septadas en ángulo dicotómico en $45^{\circ}$ en lavado broco-alveolar. Tinción de G-G. 100X.
Obtención de la muestra: En el AT se debe introducir un catéter de aspiración, estéril, a través del tubo endotraqueal o de la traqueostomía y se aspiran las secreciones respiratorias en cantidad de 3-5 cc como mínimo.

El EI se obtiene tras realizarle al paciente nebulizaciones de 10-20 $\mathrm{ml}$ de solución salina hipertónica estéril. Debe hacerse con una meticulosa técnica de aseo bucal y de recogida para minimizar la contaminación.

Condiciones de almacenamiento y transporte: $\mathrm{Si}$ su traslado no es posible de efectuar inmediatamente, conservar a $4{ }^{\circ} \mathrm{C}$ hasta 2 a $4 \mathrm{~h}$. Deberá ser remitida al laboratorio con unidad refrigerante.

Procesamiento: No centrifugar ni diluir la muestra, realizar visión microscópica directa con $\mathrm{KOH} 20 \%$ y sembrarla en dos tubos de AS a $37^{\circ} \mathrm{C}$ por 7 días.

\section{Biopsias}

Objetivo: Observación de hifas en los tejidos teñidos y desarrollo de las distintas especies en el cultivo.

Obtención de la muestra: Una vez obtenida la muestra (según protocolos del laboratorio de origen), ésta deberá depositarse en un frasco estéril con tapa rosca conteniendo solución salina estéril. En ningún caso con líquidos fijadores (por ejemplo formalina).

Condiciones de almacenamiento y transporte: si su traslado no es posible de efectuar inmediatamente, conservar a $4{ }^{\circ} \mathrm{C}$ hasta 2 a $4 \mathrm{~h}$. Deberá ser remitida al laboratorio con unidad refrigerante.

Procesamiento: un trozo de la muestra sin fijar se cultivará en uno o dos tubos de AS a $37^{\circ} \mathrm{C}$ durante 7 días, sin macerar o moler el tejido, ya que puede afectar el desarrollo de los distintos hongos filamentosos. El otro trozo se enviará a anatomía patológica con fijador para tinción con Gomori-Grocott (G-G), hematoxilina eosina (HE) y/o ácido peryódico de Schiff (PAS).

\section{Otros líquidos o secreciones}

En caso de obtener muestra de líquido pleural, peritoneal, lesiones de piel u otras para examen microscópico directo y cultivos, las condiciones de almacenamiento, transporte y procesamiento deben ser similares a las muestras descritas previamente.

\section{Interpretación e informe}

Informe del examen microscópico directo de LBA, aspirado traqueal, esputo y microscópico de las biopsias.

Se deberá describir la presencia de hifas, su diámetro, ramificación, la presencia de septos o su ausencia, si el micelio es hialino o dematiáceo. De ninguna manera se podrá informar género o especie con estos datos. Aspergillus en general producen hifas tabicadas hialinas de 2 a 4 um de diámetro que se ramifican dicotomicamente en $45^{\circ}$ (Figura 1), al igual que Fusarium, Scedosporium, 


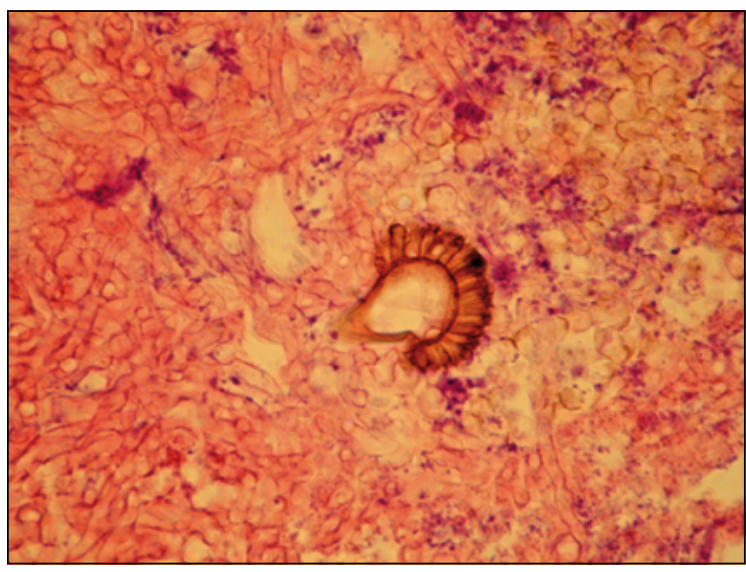

Figura 2. Aspergillus monoseriado estricto en bola fúngica pulmonar. Tinción PAS. 100X.

entre otros géneros. La presencia de otras estructuras fúngicas como conidióforos, vesículas, fialides o conidios, se observan muy raramente en las muestras y pueden ser vistas en algunas lesiones cavitadas que comunican directamente con el árbol traqueo-bronquial (Figura 2). Los hongos inferiores (Rhizopus spp, Lichtheimia spp, Mucor spp) producen hifas no septadas, de pared gruesa, algunas de las cuales pueden mostrar ramificaciones en $90^{\circ}$ (Figura 3). Se debe tener en cuenta que en tejidos la morfología típica de los hongos se puede perder, razón por la cual el cultivo resulta fundamental en la identificación del género y especie.

\section{Informe de cultivos}

Siempre se debe diferenciar entre hongos superiores e inferiores. Los hongos superiores presentan en el micelio septos en forma regular y éste puede ser hialino o dematiáceo. Dentro de los hongos hialinos los géneros más frecuentes son Aspergillus y Fusarium (Figura 4). Entre los dematiáceos destacan Alternaria (Figura 5), Curvularia y Scedosporium.

Por su parte los hongos inferiores (mucormycetes) se diferencian del resto de hongos filamentosos por presentar hifas anchas, ramificadas, generalmente no septadas y esporas sexuales denominadas zigosporas. Dentro de este grupo destacan los géneros Rhizopus, Lichtheimia y Mucor. Rhizopus se caracteriza por presentar un esporangio $\mathrm{y}$ esporangioforo que nacen de un rizoide, los cuales se unen por estolones. Lichtheimia se caracteriza por tener esporangioforos desarrollándose a partir de los estolones y entre los rizoides, solitarios o en grupos, de hasta 450 $\mu \mathrm{m}$ de longitud, generalmente ramificados, con apófisis de forma cónica (Figura 6). Mucor presenta un esporangio sin apofisis, con esporangioforos que nacen directamente del sustrato y no presenta rizoides ni estolones.

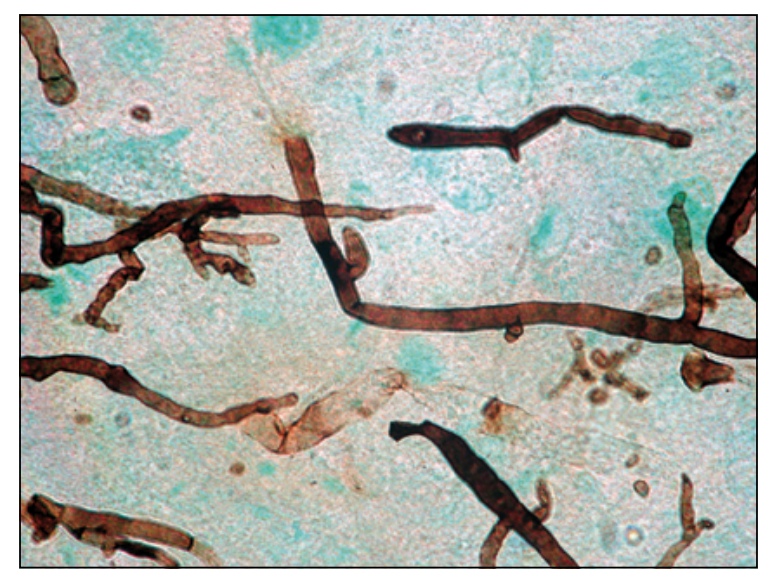

Figura 3. Hifas anchas y $\sin$ septos de hongo inferior en aspirado traqueal. Tinción G-G.100X.

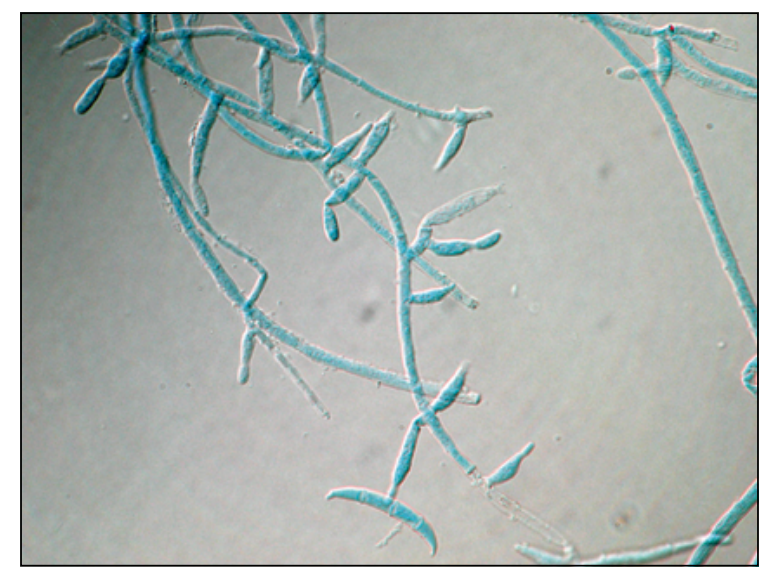

Figura 4. Hifas septadas con fialides y macroconidios falcados de Fusarium oxysporum. Cultivo en agar clavel. Tinción de lactofenol con azul de algodón. 100X.

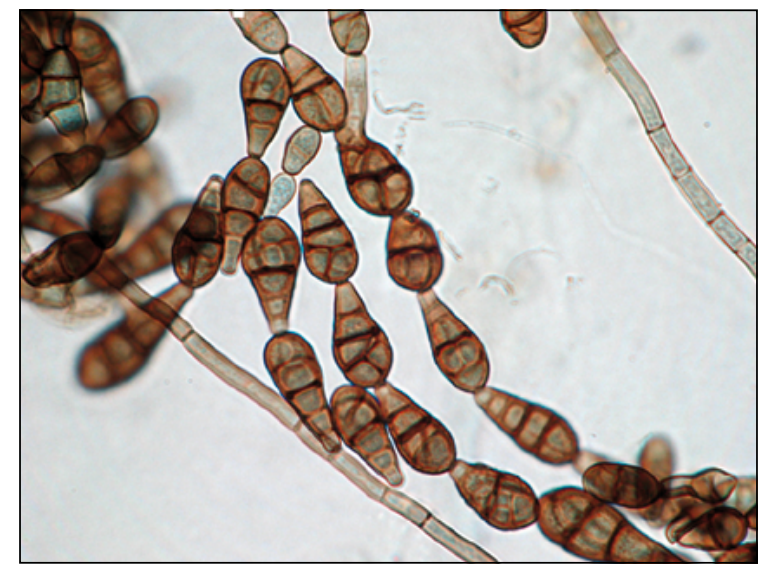

Figura 5. Dictioconidios café oscuros en cadenas de Alternaria alternata. Cultivo en agar harina de maíz. Tinción de lactofenol con azul de algodón. 100X.

\section{Identificación de las especies más comunes del género Aspergillus}

Para poder identificar el género y especies se debe contar con lupa estereoscópica, microscopio de luz con regla o micrómetro ocular y cámaras de cultivos.

Una vez logrado el desarrollo de la especie en AS, 
traspasar la cepa a agar extracto de Malta (MEA) y en agar Czapek Levadura (CYA) (Anexo 1) durante 7 días. Para la identificación morfo-fisiológica se recomienda seguir las claves dicotómicas descritas por Piontelli $\mathrm{E}^{21}$; sin embargo, a continuación se describen algunas claves para la identificación de las principales especies involucradas en EFI en humanos.

Aspergillus fumigatus: colonias en CYA con diámetro entre 45 y $75 \mathrm{~mm}$, de color turquesa o verde oscuro, de textura aterciopelada a flocosas, planas o radialmente surcadas, cleistotecios ausentes; cabezas conidiales columnares, con vesículas clavadas; estipe incoloro a gris cerca del ápice; vesículas uniseriadas estrictas con fiálides que cubren la mitad o la tercera parte de esta, dispuestas en forma paralela con el eje del estipe; conidios globosos o elipsoides, lisos a finamente rugosos, de 2-3 $\mu \mathrm{m}$ en diámetro (Figura 7).

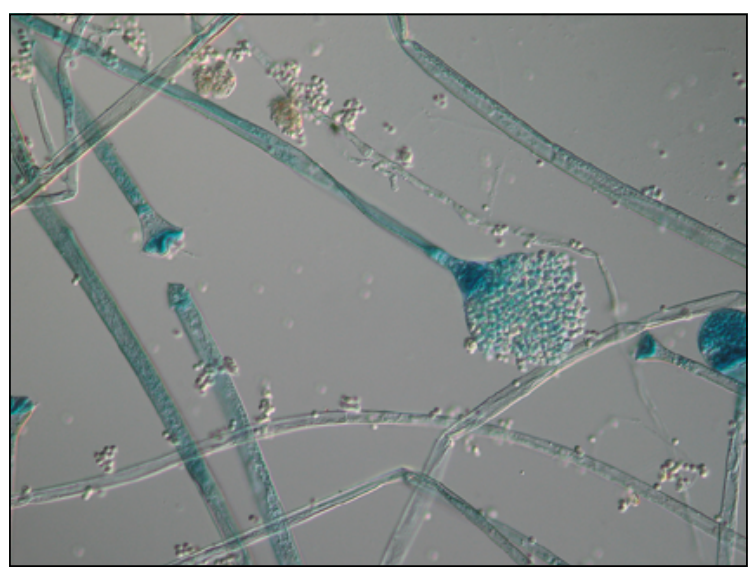

Figura 6. Esporangio y esporangioforo con apófisis de forma cónica de Lichtheimia corymbifera. Cultivo en AS. Tinción de lactofenol con azul de algodón. 100X.

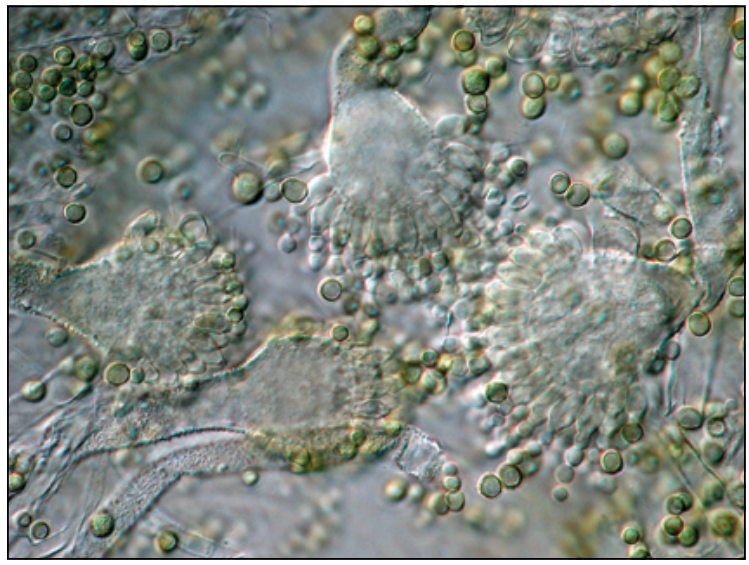

Figura 8. Cabezas conidiales monoseriadas de Aspergillus flavus en MEA. Tinción de lactofenol con azul de algodón.100X.
Aspergillus flavus: Colonias de color oliva verde a verde amarillento en CYA, diámetro de éstas, en todos los medios y temperaturas, mayores de $50 \mathrm{~mm}$, esclerocios generalmente presentes, redondos de colores café, violeta a negros; cabezas conidiales radiadas a columnares laxas; estipe rugoso, incoloro, a veces en tonos café pálidos; vesículas biseriadas generalmente en $20 \%$, pero variable, en MEA a veces enteramente uniseriadas, con métulas/ fiálides que cubren los 3/4 de la vesícula; conidios globosos a elipsoides 3- $6 \mu \mathrm{m}$ (Figura 8).

Aspergillus niger: Colonias de color café oscuro, con diámetro en CYA entre 50 y $70 \mathrm{~mm}$; cabezas conidiales café oscuras a negras, biseriadas; conidios globosos, irregularmente rugosos a finamente rugosos, con crestas y surcos de 3,5-5 $\mu \mathrm{m}$ de diámetro (Figura 9).

Aspergillus nidulans: Colonias verde oscuro, crecimiento en CYA entre 40 y $60 \mathrm{~mm}$ y MEA 53 a $65 \mathrm{~mm}$,

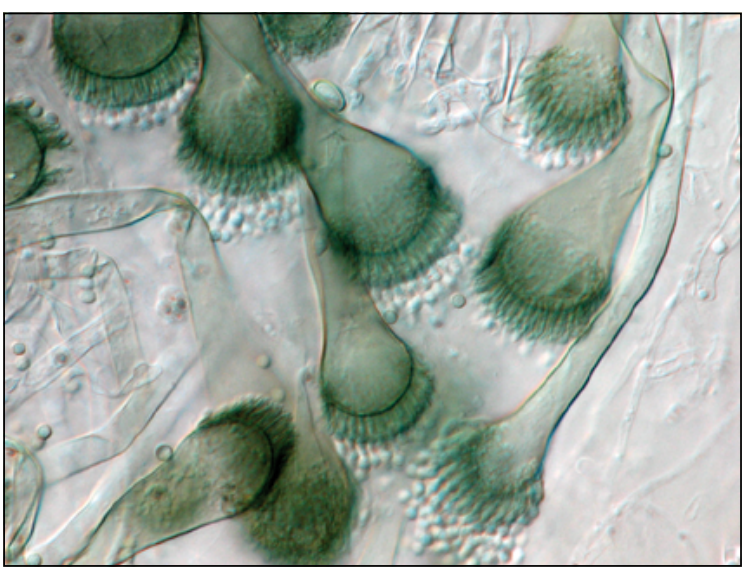

Figura 7. Cabezas conidiales monoseriadas estrictas de Aspergillus fumigatus en MEA. Tinción de lactofenol con azul de algodón.100X.

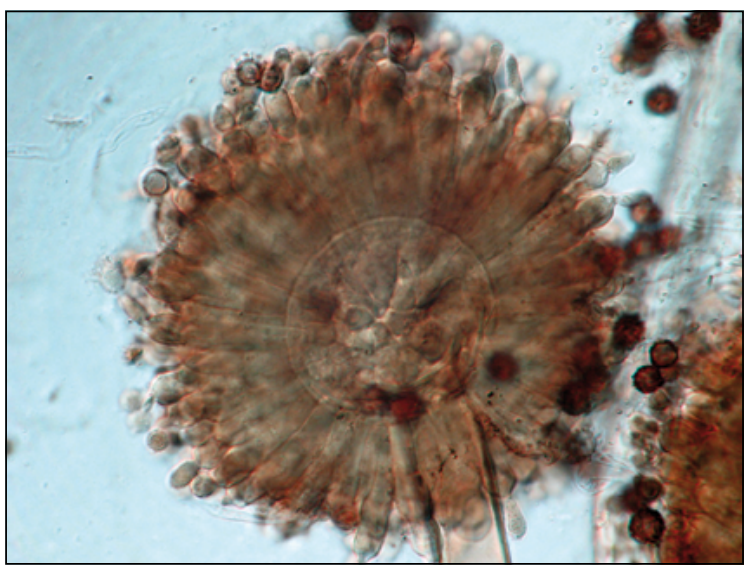

Figura 9. Cabeza conidial con microconidios café oscuros y rugosos de Aspergillus niger en MEA. Tinción de lactofenol con azul de algodón.100X. 
cleistotecios de Emericella a menudo presentes, globosos, de paredes de color rojo oscuras al madurar, recubiertas por células de Hülle de color amarillo. Ascosporas (maduran a las dos semanas), redondas a lenticulares en vista lateral, rojo púrpura, lisas, 4-6 x 3-4 $\mu \mathrm{m}$ con dos rebordes finos longitudinales de cerca de $1 \mu \mathrm{m}$ (Figura 10); conidióforos cortos de color café; cabezas conidiales biseriados con métulas que cubren la mitad superior de la vesícula; conidios esféricos, lisos a finamente rugosos de 3-4 $\mu \mathrm{m}$ (Figura 11).

Aspergillus terreus: Colonias color canela-café a café rosado, con diámetro en CYA entre 60 y $70 \mathrm{~mm}$. Cabezas conidiales columnares, a menudo biseriadas, métulas angostas compactadas $(2-2,5 \mu \mathrm{m})$ que cubren las $3 / 4$ partes de la vesícula; conidios globosos a elipsoides, lisos con diámetro entre 2-2,5 $\mu \mathrm{m}$ (Figura 12). Células globosas hialinas (aleuroconidios) adheridos lateralmente en las hifas sumergidas, usualmente presentes.

\section{Deteccion de galactomanano}

La detección del exo-antígeno galactomanano liberado de la pared de las distintas especies de Aspergillus durante la angioinvasión se realiza por ensayo inmunoenzimático tipo sandwich en microplacas, ya sea en suero o en LBA, tanto en niños como en adultos. Las condiciones de almacenamiento, transporte y procesamiento son fundamentales en los resultados de este examen.

Tipos de muestras, condiciones de almacenamiento, transporte y procesamiento

\section{Sangre}

Objetivo: Detección del exo-antígeno galactomanano de la pared de las especies de Aspergillus.

Obtención de la muestra: tomar una muestra de sangre de aproximadamente $5 \mathrm{cc}$, en tubos con gel y tapón hermético (tapa amarilla).

Condiciones de almacenamiento y transporte: Los tubos con la muestra pueden ser almacenados sin ser abiertos entre 2 y $8{ }^{\circ} \mathrm{C}$ hasta 5 días antes del estudio y deben ser transportados con cadena de frío hasta el laboratorio. Opcionalmente puede ser enviado centrifugado a $3.000 \mathrm{rpm}$ por $10 \mathrm{~min}$.

Procesamiento: Si no fue centrifugado anteriormente, hacerlo a $3.000 \mathrm{rpm}$ por $10 \mathrm{~min}$. Se debe contar con el equipamiento necesario para procesar ELISA (incubadora de microplacas, centrifuga de microtubos que alcance los $10.000 \mathrm{rpm}$, baño de flotación a $100^{\circ} \mathrm{C}$ y lector de microplacas con filtro entre 450 y $620 \mathrm{~nm}$ ). Los resultados no se afectan en muestras que contienen $20 \mathrm{mg} / \mathrm{L}$ de bilirrubina, muestras lipémicas con $2 \mathrm{~g} / \mathrm{L}$ de trioleía (triglicérido) o hemolizadas que contengan $165 \mathrm{mg} / \mathrm{L}$ de hemoglobina. No requiere eliminar el complemento de los sueros.

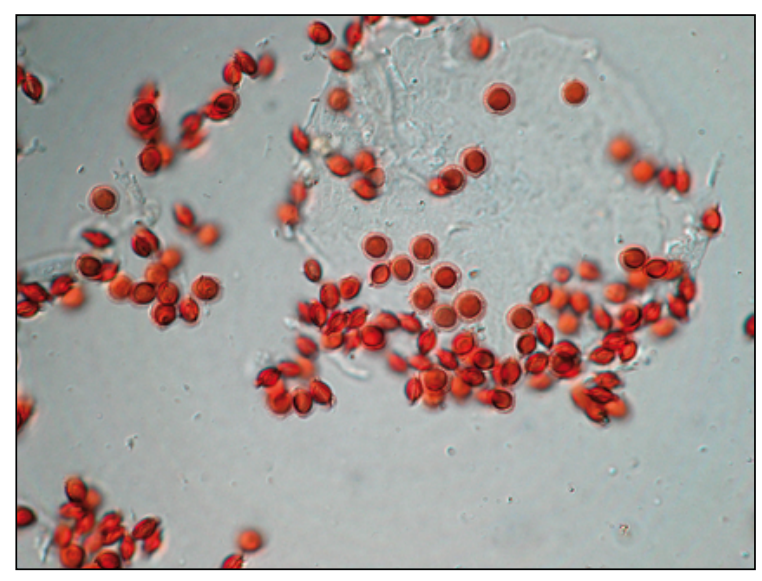

Figura 10. Ascosporas redondas a lenticulares de color rojo púrpura de Emericella nidulans en MEA. Tinción de lactofenol con azul de algodón.100X.

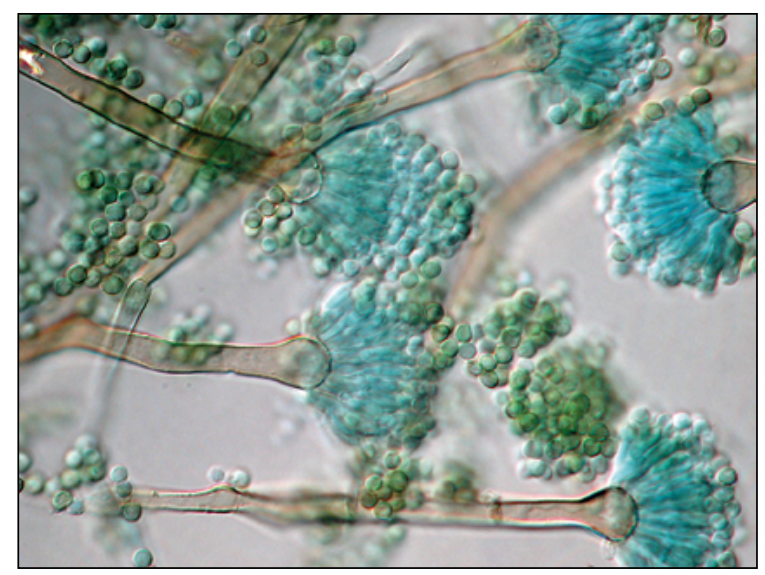

Figura 11. Conidioforos cortos de color café y cabezas conidiales biseriados con métulas que cubren la mitad superior de la vesícula de Aspergillus nidulans en MEA. Tinción de lactofenol con azul de algodón.100X.

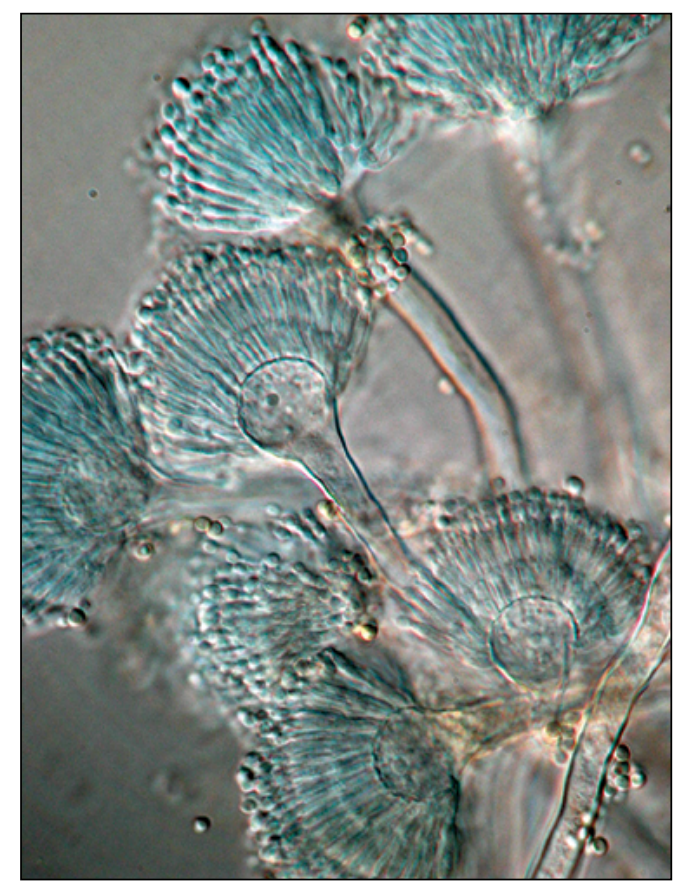

Figura 12. Cabezas conidiales columnares, biseriadas, con métulas angostas compactadas que cubren las $3 / 4$ de la vesícula de Aspergillus terreus en MEA. Tinción de lactofenol con azul de algodón.100X. 


\section{Lavado bronco-alveolar}

Objetivo: Detección del exo-antígeno galactomanano de la pared de las especies de Aspergillus.

Toma de la muestra: Mediante fibrobroncoscopio impactado en un bronquio sub-segmentario, se instila solución salina ( $\mathrm{NaCl}$ 9\%o estéril) entre 50 y $100 \mathrm{ml}$. Las muestras deben ser recolectadas en tubos estériles con tapa rosca. No agregar líquido fijador alguno.

Condiciones de almacenamiento y transporte: $\mathrm{Si}$ su traslado no es posible de efectuar en el momento, conservarla a $4{ }^{\circ} \mathrm{C}$ hasta $24 \mathrm{~h}$, debido a que aumenta el riesgo de crecimiento de otros hongos y bacterias contaminantes. Para conservación más prolongada (hasta 5 meses) se puede congelar a $-20^{\circ} \mathrm{C}$. Debe ser enviada al laboratorio con unidad refrigerante.

Procesamiento: Si no fue centrifugado anteriormente, hacerlo a $3.000 \mathrm{rpm}$ durante $10 \mathrm{~min}$. Se ocupa el sobrenadante del centrifugado, a diferencia del cultivo donde se trabaja con el pellet. Se debe contar con el mismo equipamiento descrito anteriormente para el procesamiento de sangre.

\section{Interpretación del informe}

En sangre se considerará como positivo un índice mayor de $0,5^{15}$. En el caso de realizarlo en LBA se considerará positivo un índice mayor de $1^{16}$. Sin embargo, es necesario considerar los valores del examen en el tiempo con al menos dos pruebas semanales, más que un solo valor aislado.

Falsos negativos: Pacientes con enfermedad granulomatosa crónica o enfermedad de Job, aspergilosis localizadas como traqueo-bronquitis, profilaxis o uso empírico de antifungicos activos contra Aspergillus e infecciones por especies menos reactivas como A. fumigatus, por lo que valores limites deben ser interpretados según las señas clínicas y otros exámenes complementarios ${ }^{22,23}$.

Falsos positivos: Neonatos colonizados con Bifidobacterium spp, infección por otros hongos filamentosos de los géneros Penicillium, Alternaria, Histoplasma o Geotrichum, uso concomitante de piperacilina/tazobactam y consumo de productos lácteos o cereales con galactofuranosa ${ }^{22,23}$.

\section{Comentario final}

El diagnóstico de EFI por años ha sido dificultoso y tardío; no obstante, tal como lo describe esta guía, en la actualidad contamos con la detección de galactomanano por ensayo inmunoenzimatico, lo que sumado a la optimización del examen microscópico directo, cultivos y biopsias, nos dan la oportunidad de realizar un diagnóstico oportuno y así poder indicar un tratamiento precoz, con el fin de mejorar la sobrevida de nuestros pacientes.

Agradecimientos. A los miembros de la Red de Vigilancia de Enfermedades Fúngicas Invasoras de Isla Seca, Chile, por estimular la escritura de este artículo y por su generosa ayuda.

\section{Resumen}

La enfermedad fúngica invasora (EFI) por hongos filamentosos es causa de morbi-mortalidad en pacientes inmunocomprometidos, por lo que es fundamental el diagnostico precoz y su tratamiento oportuno. Las manifestaciones clínicas de las EFIs son inespecíficas, razón por la cual las imágenes (TAC), el examen microscópico directo, tinciones y cultivos de las muestras obtenidas y la determinación de galactomanano en sangre o en LBA tienen un rol fundamental. Esta guía tiene por objetivo recomendar las óptimas condiciones de transporte, procesamiento de las muestras, así como las tinciones y los medios de cultivos a utilizar. Se describen, además, claves para el diagnóstico de los principales géneros y especies de Aspergillus.

Anexo 1. Medios de cultivos mínimos con que se debe contar para la identificación de Aspergillus spp

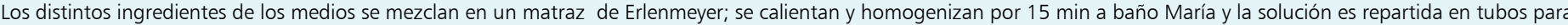

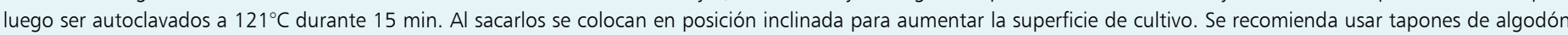

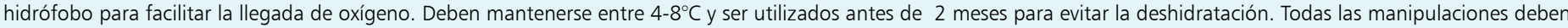
realizarse bajo llama de mechero Bunsen o en una campana de flujo laminar.

1. Agar Sabouraud (AS)

Peptona

Glucosa

Agar

Cloranfenicol

Agua destilada
2. Agar extracto de Malta (MEA)

$10 \mathrm{~g}$

$40 \mathrm{~g}$

$15 \mathrm{~g}$

$125 \mathrm{mg}$

$1.000 \mathrm{ml}$

Extracto de malta en polvo $20 \mathrm{~g}$

Glucosa

Agar

Agua destilada
3. Agar Czapek Levadura (CYA25)

\section{K2HPO4}

Concentrado de Czapek $10 \mathrm{ml}$

Extracto de levadura $\quad 5 \mathrm{~g}$

Sucrosa

$20 \mathrm{~g}$

$1.000 \mathrm{ml}$
Agar

Agua destilada
4. Concentrado de Czapek (con trazas de metales) $\mathrm{NaNO} 30 \mathrm{~g}$

$\mathrm{KCl} \quad 5 \mathrm{~g}$

$\mathrm{MgSO} 4.7 \mathrm{H} 2 \mathrm{O} \quad 5 \mathrm{~g}$

FeSO4. TH2O $\quad 0,1 \mathrm{~g}$

ZnSO4. TH2O $\quad 0,1 \mathrm{~g}$

CuSO4. $5 \mathrm{H} 2 \mathrm{O} \quad 0,1 \mathrm{~g}$ 


\section{Referencias bibliográficas}

1.- Ascioglu S, Rex J H, De Pauw B, Bennett J E, Billc J, Crokaert F, et al. Defining opportunistic invasive fungal infections in immunocompromised patients with cancer and hematopoietic stem cell transplants: An International Consensus. Clin Infect Dis 2002; 34: 7-14.

2.- Horn D L, Neofytos D, Anaissic E J, Fishman J A, Steinbach W J, Olyaci A J, et al. Epidemiology and outcomes of candidemia in 2019 patients: data from the prospective antifungal therapy alliance registry. Clin Infect Dis 2009; 48: 1695-703.

3.- Chamilos G, Luna M, Lewis R E, Bodey G P, Chemaly R, Tarrand J J, et al. Invasive fungal infections in patients with hematologic malignancies in a tertiary care cancer center: an autopsy study over a 15 year period (1989-2003). Hematological 2006; 91: 986-9.

4.- Enoch D A, Ludlam H A, Brown N M. Invasive fungal infections: a review of epidemiology and management options. J Med Microbiol 2006; 55: 809-18.

5.- Cruz R, Piontelli E. Enfermedad fúngica invasora (EFI) en pacientes de cinco hospitales de la Quinta Región de Valparaíso, Chile. 2004 a 2009. Rev Chilena Infectol 2011; 28 (2): 123-9.

6.- Rabagliati R, Fuentes G, Guzmán A M, Orellana E, Oporto J, Aedo I, et al. Enfermedad fúngica invasora en pacientes hemato-oncológicos y receptores de trasplante de precursores hematopoyéticos bajo la perspectiva de los criterios diagnósticos EORTC/MSG. Rev Chilena Infectol 2009; 26 (3): 212-9.

7.- García-Ruiz J C, Amutio E, Ponton J. Infección fúngica invasora en pacientes inmunodeficientes. Rev Iberoam Micol 2004; 21: 55-62.
8.- Singh N, Paterson D L. Aspergillus infections in transplant recipients. Clin Microbiol Rev 2005; 18: 44-69.

9.- Caillot D, Couaillier J F, Bernard A, Casasnovas O, Denning D W, Mannone L, et al. Increasing volume and changing characteristics of invasive pulmonary aspergillosis on sequential thoracic computed tomography scans in patients with neutropenia. J Clin Oncol 2001; 19: 253-9.

10.- De Pauw B, Walsh T J, Donnelly P, Stevens D A, Edwards J E, Calandra T, et al. Revised definitions of invasive fungal disease from the European Organization for Research and Treatment of Cancer/Invasive Fungal Infections Cooperative Group and the National Institute of Allergy and Infectious Diseases Mycoses Study Group (EORTC/MSG) Consensus Group. Clin Infect Dis 2008; 46: 1813-21.

11.- Herbrecht R, Denning D W, Patterson T F, Bennett J E, Greene R E, Oestmann J-W, et al. Voriconazole versus amphotericin $\mathrm{B}$ for primary therapy of invasive aspergillosis. N Engl J Med 2002; 347: 408-15.

12.- Patterson T F, Kirkpatrick W R, White M, Hiemenz J W, Wingard J R, B Dupont, et al. Invasive aspergillosis. Disease spectrum, treatment practices and outcomes. Medicine 2000; 79: 250-60.

13.- Caillot D, Casanovas O, Bernard A, Couailler J F, Durand C, Cuisenier B, et al. Improved management of invasive aspergillosis in neutropenic patients using early thoracic computed tomographic scan and surgery. J Clin Oncol 1997; 15: 139-47.

14.- Reichenberger F, Habicht J M, Gratwohl A, Tammz M. Diagnosis and treatment of invasive pulmonary aspergillosis in neutropenic patients. Eur Respir J 2002; 19: 743-55.

15.- Maertens J, Verhaegen J, Lagrou K, Van Eldere J, Boogaerts M. Screening for circulating galactomannan as a noninvasive diagnostic tool for invasive aspergillosis in prolongued neutropenic patients and stem cell transplantation recipients: a prospective validation. Blood 2001; 97: 1604-10.

16.- Maertens J, Maertens V, Theunissen K, Meersseman W, Meersseman P, Meers S, et al. Bronchoalveolar lavage fluid galactomannan for the diagnosis of invasive pulmonary aspergillosis in patients with hematologic diseases. Clin Infect Dis 2009; 49 (11): 1688-93.

17.- Desai R, Ross L, Hoffman J. The role of bronchoalveolar lavage galactomannan in the diagnosis of pediatric invasive aspergillosis. Pediatr Infect Dis J 2009; 28: 283-6.

18.- Leeflang M M, Debets-Ossenkopp Y J, Visser C E, Scholten R J, Hooft L, Bijlmer H A, et al. Galactomannan detection for invasive aspergillosis in immunocompromized patients. Cochrane Database Syst Rev 2008; p. CD007394.

19.- Pemán J. ¿Qué se puede esperar del diagnóstico micológico clásico de la aspergilosis invasora? Aspergilosis invasora. Guía de bolsillo. Editor: José Pontón 2003; 47-50.

20.- Cruz R, Vieille P, Fuentes D, Ponce E, Piontelli E. Micosis pulmonares en pacientes de la Quinta Región: Período 2007-2010. Rev Med Chile 2012; 140 (5): 595-601.

21.- Piontelli E. Aportes morfotaxonómicos en el genero Aspergillus Link: claves para las especies ambientales y clínicas más comunes. Bol Micol 2008; 23: 49-66.

22.- Khanna S, Oberoi J K, Datta S, Aggarwal S, Wattal C. Variables affecting the performance of galactomannan assay in high-risk patients at a Tertiary Care Centre in India. Indian J Med Microbiol 2013; 31 (1): 34-9.

23.- Marr K A, Balajee S A, McLaughlin L, Tabouret M, Bentsen C, Walsh T J. Detection of galactomannan antigenemia by enzyme immunoassay for the diagnosis of invasive aspergillosis: variables that affect performance. J Infect Dis 2004; 190: 641-9. 